\title{
Radon induced hyperplasia may provide an explanation for inverse exposure rate effect
}

\author{
Balázs Madas", and Emese Drozsdik \\ MTA Centre for Energy Research, Environmental Physics Department, Konkoly-Thege Miklós út 29- \\ 33, 1121 Budapest, Hungary
}

\section{Introduction}

In most cases, incorporation of radionuclides results in protracted exposures. It means that adaptive responses may affect the health consequences more significantly than in case of acute exposures. It is reasonable to assume that a given dose results in lower risk if the dose rate is lower and the duration is longer, as it is reflected in the application of the dose and dose rate effectiveness factor (DDREF) [1]. In case of inhaled radon progeny, however, there is evidence for an inverse exposure rate effect [2] meaning that longer duration and lower exposure rate results in higher risk for a given exposure.

Inhalation of radon progeny is characterized by highly heterogeneous dose distribution within the bronchial airways [3]. While the spatial and temporal distribution of dose does not modulate biological effects which show linear dose dependence, they may have significant impact in case of non-linear biological responses to ionizing radiation such as radioadaptive responses. Histological and experimental studies show that different cell types increase in number in response to a wide variety of drugs and irritants $[4,5]$ resulting in hyperplasia in the bronchial epithelium. Although there is no direct evidence for the induction of hyperplasia upon radon exposure, theoretical considerations about its effectiveness in adaptation to extensive cell loss [6] supports the idea that hyperplasia occurs in the deposition hot spots upon chronic exposures to radon progeny, as well.

The objectives of the present study are to quantify how the induction of hyperplasia modulates the microdosimetric consequences of a given (macroscopic) exposure and to discuss whether the phenomenon can provide a link between two characteristics of radon exposure: heterogeneity in dose distribution and inverse exposure rate effect.

\section{Methods}

Based on histological data $[7,8]$, computational epithelium models with different thickness and different abundance of basal and goblet cells were prepared to represent different measures of hyperplasia. Spherical cell nuclei of six different cell types were considered. As goblet cells play a major role in mucus production, the thickness of mucus layer covering the epithelium was supposed to be proportional to goblet cells number. Applying Monte-Carlo codes, cellular burdens such as cell nucleus hits and cell nucleus doses were quantified for the deposition hot spots, where local doses can be two orders of magnitude

*Corresponding author: balazs.madas@energia.mta.hu 
higher than the average over the airway generation [3]. Besides average cell nucleus hits and dose, distribution of hit numbers and doses of cell nuclei were determined.

\section{Results and discussion}

Results show that average tissue dose, average hit number and dose of basal cells decrease by the increase of the measure of both basal and goblet cell hyperplasia $[9,10]$. Hit and dose distributions reveal that the induction of hyperplasia may result in a basal cell pool which is shielded from alpha-particles in particular in case of goblet cell hyperplasia where both mucus thickening and the additional number of goblet cells decrease cellular burdens.

The induction of hyperplasia points out that the exposure history affects the microdosimetric consequences of a present exposure. It can be considered as a radioadaptive response at the tissue level which challenges the validity of the application of the dose and dose rate effectiveness factor from a mechanistic point of view.

As the location of radiosensitive target cells may change due to previous exposures, dosimetry models considering the tissue geometry characteristic of normal conditions may be inappropriate for dose estimation in case of protracted exposures. As internal exposures are frequently chronic, such changes in tissue geometry may be highly relevant for other incorporated radionuclides too.

Based on theoretical considerations [6], it is expected that the measure of hyperplasia increases by exposure rate. As the increased measure of hyperplasia results in lower dose rates, a given total exposure can cause more genetic damage in the tissue if the duration is longer and the exposure rate is smaller. In this way, the induction of hyperplasia can provide an explanation for inverse exposure rate effect. In addition, this kind of adaptation of the tissues may also play a role in the observation that heterogeneous exposures result in lower risk compared to homogeneous exposures as it is seen in case of hot particles [11].

This work was supported by the National Research, Development and Innovation Office under the contract VKSZ_14-1-2015-0021.

\section{References}

[1] International Commission on Radiological Protection, Ann ICRP, 37 (2007) 1-332.

[2] J.H. Lubin, J.D. Boice, C. Edling, R.W. Hornung, G. Howe, W. Kunz, R.A. Kusiak, H.I. Morrison, E.P. Radford, J.M. Samet, M. Tirmarche, A. Woodward, S.X. Yao, Health Phys, 69 (1995) 494-500.

[3] I. Balásházy, Á. Farkas, B.G. Madas, W. Hofmann, J Radiol Prot, 29 (2009) 147-162.

[4] D.F. Rogers, Int J Biochem Cell Biol 35 (2003) 1-6.

[5] I.O. Gordon, S. Sitterding, A.C. Mackinnon, A.N. Husain, Arch Pathol Lab Med, 133 (2009) 1106-1115.

[6] A.D. Lander, K.K. Gokoffski, F.Y.M. Wan, Q. Nie, A.L. Calof, PLoS Biol, 7 (2009) e15.

[7] R.R. Mercer, M.L. Russell, J.D. Crapo, Health Phys, 61 (1991) 117-130.

[8] R.R. Mercer, M.L. Russell, V.L. Roggli, J.D. Crapo, Am J Respir Cell Mol Biol, 10 (1994) 613-624.

[9] B.G. Madas, J Radiol Prot, 36 (2016) 653-666.

[10] B.G. Madas, E.J. Drozsdik, Int J Radiat Biol, 94 (2018) 967-974.

[11] M.W. Charles, A.J. Mill, P.J. Darley, J Radiol Prot, 23 (2003) 5-28. 